\section{A phenomenological reading of anomalous monism}

\section{Andrea Zhok}

In Mental Events (1970) Donald Davidson proposed a theory concerning the relationship between mental and physical events, which he named "anomalous monism"; this theory has been thoroughly discussed in the last decades and has been re-exposed and qualified by Davidson himself in many writings. Nevertheless it is hard to say that anomalous monism has ever reached a fully settled interpretive status: several powerful criticisms notwithstanding, the argument as a whole remains attractive and intuitively persuasive to many philosophers. In the following pages I am not going to provide a further immanent reading of Davidson's reasoning with the aspiration to discover either an unexplored strand of objections or a tighter and smarter account of the same reasoning. Instead, I will discuss anomalous monism as an exemplary attempt to deal with the relationship between the physical and the mental within a physicalist framework and I will try to interpret it in the framework of Husserlian phenomenology. The mention of Husserl's phenomenology in connection with Davidson may sound like a strained pairing, yet, granted that the differences in philosophical style could hardly be greater, the Husserlian position on the mental/physical relationship has been itself authoritatively understood as a kind of "anomalous monism" (cf. Smith D.W., 1995: 362f) and this for good reasons. I believe that reading the Davidsonian argument for anomalous monism through the lens of Husserlian phenomenology can be fruitful for both approaches with reference to the conceptualization of the mental and the physical, and with particular reference to the controversial issue of mental causation.

\section{The argument for anomalous monism}

The core structure of the argument for anomalous monism consists of three theses that seem at first sight incompatible. The first thesis is called by Davidson the principle of Causal Interaction (CI) and says that "mental events interact causally with physical events" (Davidson 1970, p. 208). This seems prima facie uncontroversial: perception shows how mental events can be caused by physical events, and human actions are instances of mental events causing physical events. The second thesis is called the principle of the Nomological Character of Causality (NC) and states that "events related as cause and effect fall under strict deterministic laws" (ibid.). The basic idea is that each singular causal statement is to be subsumed under a covering law -- a strict law -- which is predictive, like the laws deployed by physical science. The third thesis is the principle of the Anomalism of the Mental (AM), which states that "there are no strict deterministic laws on the basis of which mental events can be predicted and explained" (ibid.). At first glance the three theses seem to be mutually incompatible, since it seems that from CI and NC one must draw the conclusion that mental events should fall under strict laws, which contradicts AM. However Davidson rejects such incompatibility by arguing as follows:
Formattato: Giustificato, Interlinea: singola Formattato: Sinistro: $3,8 \mathrm{~cm}$, Destro $3,8 \mathrm{~cm}$, Superiore: 3 $\mathrm{cm}$, In basso: $3 \mathrm{~cm}$

Eliminato: read

Eliminato: labelled itself

Eliminato: and can provide some new perspectives on

Eliminato: This constitutive connection between singular causal statements and strict laws has repeatedly been object of criticism, and we will see how Davidson tries to defend it. 
Causality and identity are relations between individual events no matter how described. But laws are linguistic; and so events can instantiate laws, and hence be explained or predicted in the light of laws, only as those events are described in one or another way. The principle of causal interaction deals with events in extension and is therefore blind to the mental-physical dichotomy. The principle of the anomalism of the mental concerns events described as mental, for events are mental only as described. (1970, p. 215)

In other words, $\mathrm{NC}$ implies only that events de facto related as cause and effect have descriptions that instantiate a law; it does not imply that whenever events respectively describable as mental and physical causally interact, this interaction instantiates a law. Laws depend on how events are actually described and, according to Davidson, when we describe events as mental we provide a characterization that does not allow these events to be subsumed under strict laws.

Of course the Anomalism of the Mental could be straightforwardly argued for in a dualistic framework, but one of the striking features of Davidson's reasoning is that AM together with CI and NC is actually used to support monism, by which Davidson means a theory of the identity of mental and physical events. The argument runs as follows; if psychological events causally interact with physical events [CI], the second principle [NC] implies that there are strict laws that cover them. But by the third principle [AM], those, laws cannot be, psychophysical, "so they must be purely physical laws." (1974, p. 231) The conclusion is monistic because it holds that psychological events are physical events, even if mental events, when described as such, do not fall under strict laws, Thus, Davidson states the anomalism of the mental as an a priori thesis in a physicalistic framework, which is notoriously, a framework that is most often regarded as conducive to reductionist positions.

Many objections have been raised against anomalous monism, among which the most persistent and comprehensive one is the charge of entailing the epiphenomenalism of mental properties. It has been argued that under the premises of anomalous monism no causal powers are left to mental events, since causality is to be attributed to the extensional dimension belonging to physical events. So, for instance, Jaegwon Kim (2000, p. 37) has noticed that, if we assume that an event $p$ is caused by a mental event $m$, then, since we must admit that $p$ has_also a physical cause (which must be granted, if the physical domain is to be considered a closed system), then it is obscure "what causal work is left for $m$ to contribute" (see also Honderich 1988, p. 94). It seems that mental events should not play any substantial causal role, but this conclusion, if accepted, would contradict the principle of Causal Interaction invoked by Davidson as first premise of his argument. In order to clarify Davidson's argument we have to clarify five notions that represent the main conceptual props supporting anomalous monism: the attributes of "mental" (1) and "physical" (2), and the ideas of "law" (3), "event" (4) and "cause" (5). 
(1) The dimension of the mental to which Davidson refers while discussing anomalous monism is the sphere of propositional attitudes (1970, p. 210); "mental" is an attribute of descriptions and it is legitimately attributed to expressions containing "at least one mental verb essentially" (1970, p. 211). It must be noticed that the mentioned specification "essentially" is necessary but problematic. Granted that the occurrence of a mental verb cannot be accidental, to claim its essential occurrence does it mean that a mental verb can legitimately occur in the relevant description or that it must occur? Neither solution seems promising: on the one hand a mental verb can legitimately occur in all descriptions, since any propositional content can be truly described by using a mental verb (I believe that water boils at $100 \mathrm{C}^{\circ}$ ). In this sense there would be no description that is not mental. On the other hand, if what is meant is that some mental verbs must occur, it is hard to see how any description would, on its own, require to be put in mental terms. Indeed, in the framework of Davidson's thought the only plausible position is that we have reasons to interpret some descriptions in certain contexts in mental terms. These reasons depend on the normative nature of the interpretation of meaningful utterances: in order to make sense of others' expressions we have to interpret them in a way that optimizes agreement (Principle of Charity). And when we do so, we produce interpretive hypotheses that necessarily have a holistic character, since "[b]eliefs and desires issue in behaviour only as modified and mediated by further beliefs and desires, attitudes and attendings, without limit." (1970, p. 217) Granted that such normative and holistic features characterize mental descriptions, this is no objective criterion for determining when a description "essentially" requires to be put in mental terms:-we can only assume that we have interest or motivation to provide some descriptions in mental terms with regard to certain contents and contexts. Once we have provided such descriptions, if we have chosen to do so, they have a normative and holistic character that represents the main basis of their irreconcilability with physical descriptions, and therefore of their anomalism.

(2) As to the determination of the physical, Davidson's characterization is not very helpful, since he merely maintains that "[p]hysical events are those picked out by descriptions or open sentences that contain only the physical vocabulary essentially." (1970, p. 211) The idea is that physical descriptions are the ones provided strictly in the language of physical science. However, this is hardly a clear-cut criterion for the physical, What properly belongs to physical vocabulary? Just physical laws expressed in symbols? It cannot be so, since we must be able to connect those abstract symbols to experiences and phenomena with specifically physical content. But as soon as we have passed the minimal threshold ideally provided by strings of uninterpreted formal symbols, we come to the terrain of the ordinary use of language, where we could regard as part of physical language all meanings that help us to fill with meaning physical symbols. But this consideration could indefinitely extend the area of "physical language". Apparently we cannot determine the sphere of the physical just by extrinsically appealing to the use of physical vocabulary. But then, how could we otherwise determine the nature of the physical? Davidson tries to provide an answer by appealing to the nature of "strict laws": physical events are events that can be explained by strict laws, which are in fact ideal

Eliminato: both required and

Formattato: Tipo di carattere: Corsivo

Eliminato: It is not enough to say that a description accidentally contains a mental verb in order to establish that it is a mental description: the mental verb must occur essentially. But when we try to see what "essentially" should mean, not everything is clear:

Formattato: Tipo di carattere: Corsivo

Eliminato: It could even be argued that any propositional content lways implicitly presupposes some propositional attitude of which it is the object (think of Frege's "judgment stroke")

Formattato: Tipo di carattere: Corsivo

Eliminato: , which cannot be formalized,

Eliminato: . Therefore

Eliminato: since it is far from clear what counts as strictly physical vocabulary and why we should apply it

Eliminato: But that

Eliminato: if physical is what has a physical description, and wh counts as physical description cannot be determined just by looking at the terms occurring in the description 
physical laws. Strict laws are laws that forego causal concepts and ceteris paribus clauses. We will deal next with the relationship between law and cause, but for the identification of the physical the reference to the absence of ceteris paribus clauses in physical laws is of special interest. Ceteris paribus clauses are clauses that rule out factors potentially interfering in a causal connection, therefore laws that can do without ceteris paribus clauses are laws "treating the universe as a closed system" (Davidson 1993, p. 191). Under these conditions, we would have a truly universal law, where the relevant physical events are fully explained without going out of the physical domain. Unfortunately, no actual physical law can warrant that there is no longer need of ceteris paribus clauses (cf. Cartwright 1980): all observations and experiments we can perform rely on local regularities that allow us to concentrate on specific changes and their possible connections, but in order to knowingly exclude all possible interferences on the law-like connection that we want to establish, we should be able to look at the observed system from the point of view of God.

Davidson defines the principle of the closure of the physical realm in the following terms: "It is a feature of physical reality that physical change can be explained by laws that connect it with other changes and conditions physically described." (1970, p. 222) But if this is "a feature of physical reality," it is definitely no feature that we can inductively draw from the observation of events. On the contrary, it seems clear that this is rather a normative ideal, and precisely an ideal that helps Davidson to determine what must count as physical in the first place. No empirically tested law can warrant that all factors possibly affecting the tested systems have been taken into account, but the principle of the causal closure of the physical requires that everything claiming to be a physical law aspires to that ideal comprehensiveness: any physical change is prompted by other physical changes, even if we do not know which ones. Indeed, over the years Davidson has repeatedly admitted that he was not dealing with actual physics but with "something that one could at best hope to find in a developed physics" (1993, p. 191). This seems to lead us to the conclusion that also the notion of the physical, and not just the notion of the mental, is constitutively normative.

(3) Let us briefly turn to the notion of law. Laws are said to bet universally quantified statements that support counterfactuals (Davidson 1995, p. 203). In this acceptation, whenever we produce an explanation endowed with predictive powers we display an instantiation of a law. In Davidson's proposal, laws are epistemic devices and not ontological assumptions; they are ways in which we provide explanatory accounts of events. Nevertheless he appears to be realist about laws of nature, since he claims that even if we do not know precisely which laws there are, we know that laws there are. This is not meant as an ontological postulate, but is a thesis drawn from our basic understanding of causal relations and counterfactual truths: whenever we interpret a succession of events in causal terms we implicitly appeal to the existence of underlying laws, even if we are unable "to dredge up a law" (Davidson 1967, p. 160)

Yet, not everything is clear in this reasoning. What does it mean that an appropriate causal law exists? To begin with, it seems that the very appeal to

Eliminato: exclude

Eliminato: But, as we will see, this is a conclusion that Davidson resists.

Formattato: Tipo di carattere: $11 \mathrm{pt}$

Formattato: Giustificato, Rientro: Sinistro: $0 \mathrm{~cm}$, Destro 0 $\mathrm{cm}$, Interlinea: singola

Eliminato: $\mathrm{N}$

Formattato: Tipo di carattere: Corsivo

Eliminato: .II

[I]t does not follow that we must be able to dredge up a law if we know a singular causal statement to be true; all that follows is that we know there must be a covering law. And very often, I think, our justification for accepting a singular causal statement is that we have reason to believe an appropriate causal law exists, though we do not know what it is.

Formattato: Tipo di carattere: $12 \mathrm{pt}$

Eliminato: II

Formattato: Giustificato, Interlinea: singola 
"laws" is overdrawn, as mere regularities are enough to justify the recognition of singular causal statements. This is the case both if we consider laws to be something ontologically subsistent (laws inherent in nature), and if we regard laws just as anthropic explanatory devices. The idea of law of nature, which is originally of theological descent (cf. Giere 1999, p. 86f.), does not merely assume that nature behaves so and so but implies that nature must behave so and so because of its subjection to the law. Granted that we have excellent reasons to wish that laws there are -- since otherwise all our acts and forecasts would be boundlessly exposed to sheer accidentality -- we must nevertheless justify our belief in such existence, beyond the recognition, of regularities, Regularities (the uniformity of nature of which Hume speaks) are phenomenal data -- that is, they concern the relationship between subject and object -whereas the realist about laws of nature must conceive of subject-independent rules governing the behaviour of objects. As van Fraassen (1989, pp. 72f, 96f) has noticed, if we want to assert the mind-independent status of laws of nature, we must (at least) identify a third factor beyond the regular conjunction of two classes of events and then see if such factor is up to the task of necessarily connecting those events. Otherwise, we have just to do with regularities and with our wish to grasp them by means of law-like statements.

If a belief in the independent existence of laws of nature proper is not easy to argue for, the existence of laws as epistemic devices is no easier to justify. How can we state, as Davidson does, that, given singular causal statements, law-like epistemic devices exist? We can at most say that, given some regularities, we will try to come up with an appropriate covering law. But why should we be certain that such a law will be found?

In Laws and Cause (1995) Davidson tries to clarify the sense in which singular causal statements entail laws. In the context of a criticism of Ducasse's notion of cause, he states that in order to establish that something is a cause or an effect we must establish its identity as event (change). He then states that we can do so only against a background held to be constant: "It is not surprising [...] that singular causal statements imply the existence of covering laws: events are changes that explain and require such explanations" (1995, p. 212). The picture that he is proposing seems to be the following: when we identify something as an event (change), we do it on the basis of what we want to explain, and consequently we choose what must count as unchanged background. Under these premises we can grant that whenever we meet a singular causal statement we are committed to the existence of appropriate covering laws. It seems clear, however, that this approach grants vast authority to our subjective (or intersubjective) interests and under, these premises, a naturalistic (objectivistic) reading of laws of nature becomes very awkward,

Yet, Davidson maintains the naturalistic framework by another route. He interprets in biological terms the role of subjective interests in our commitment to the existence of laws; in this connection, he recalls that "we are inducers from birth" and that "we build the law-like habits that promote survival and enhance life" (1995, p. 215). This is an interesting argument, but it seems to reduce the covering laws of physics to products of an epistemic process driven by basic biological interests. Even if we allow this strategy, it is
Eliminato: and it remains true that, in the presence of apparent causal connections, we are bound to recognise just the subsistence

Eliminato: and not the existence of laws of nature

Eliminato: In the absence of such

Eliminato: mere

Eliminato: desire

Eliminato: , but at the price of granting

Eliminato: . Under

Eliminato: subjectivistic

Eliminato:

Eliminato: $\mathbb{q}$

Eliminato: which "naturalizes" interests and motivations, 
hard to see how this could be conducive to a realistic understanding of laws of nature. Even if laws are still part of a naturalistic framework, they would be such only as conceptual devices produced (in the last instance) on biological grounds, and there would not be much room left for a realistic reading of their content. Especially, it does not seem that this proposal is up to the task of justifying the appeal to strict laws implicit in $\mathrm{NC}$. With regard to loose laws as much as strict ones, the fact that we are allegedly committed to the existence of such laws does not warrant either that we can find them or that they exist in themselves (in some sense).

(4) While laws belong to the explanatory sphere, the notion of cause is taken to refer to the extensional substrate that calls for a law as its explanation. Unfortunately, what is meant by "cause" is far from clear in the Davidsonian approach, and this lack of clarity rests on the ambiguity of the apparently obvious extensional character of causality. When Davidson explains CI, he exemplifies causality by referring to how sensations are caused by, the world or to how beliefs and desires cause, actions, At the same time he complains that many misunderstandings concerning $\mathrm{NC}$ depend on confusion between the extensional nature of causes, which is indifferent to how causes are described, and the nature of explanations, which describe causal relations in the terms more appropriate to explanatory interests. So, he says, "there is no room for a concept of "cause as"' (1993, p. 188): events in themselves are the protagonists of causation, not events as mental or events as physical.

However, such neat distinction between the extensional sphere of causation and its explanatory dimension is not quite transparent. If we really had to take actual event causality as something that must be exempt from all descriptions, we would be uneasy with any straightforward interpretation of CI: while at first sight it seemed perfectly clear what was meant by causal interaction between mental events and physical events, now our representation of that principle seems blurred. In fact, its proper content should actually sound something like: "we are prone to explain extensional causal interactions by describing causes and effects respectively in mental and physical terms (or vice versa)". This version of CI is consistent with the previous considerations on the crucial role of subjective (or intersubjective) interests, but it leaves our understanding of events and causes rather uncertain. Under the present premises, Davidson's account of causation should be very austere, leaving aside everything univocally attributable to how extensional relations between events are described. Such an interpretive feat is not theoretically trivial (see section 3 below), yet Davidson does not seem to worry much about it. For him, the instances of causation exemplified with reference to sensations and actions are instances of event causality, which is efficient causality between events. Sensations cause our beliefs, although they do not justify them (1983, p. 143); this is the only sense in which experience can be said to be the source of our knowledge (1982, pp. 174-5).

Still, one may wonder whether Davidson, by resorting in Quinean style to an ordinary notion of naturalistically understood causation, is being radical enough: it is hard to grant that a thesis, according to which sensations drawn from the external world are efficient causes affecting the constitution of our beliefs $s_{2}$ is untainted by epistemic considerations. If it is true, as Davidson
Eliminato: are

Eliminato: is

Eliminato: Furthermore

Eliminato: In fact, Davidson tries to justify the appeal to strict laws with reference to a commitment which would be led by "interests that are not practical," interests that would prompt us to "seek laws that have no exceptions" $(1995, \mathrm{p} .216)$. But, if this is the "ase, it becor difficult to prese of nature.

Eliminato: Needless to say, a clear grasp of the notion of cause is essential to any interpretation of anomalous monism.

Eliminato: the relation of

Eliminato: and beliefs to

Eliminato: (the external world causes beliefs through sensations)

Eliminato: the relation of

Eliminato: to

Eliminato: (reasons are causes of actions)

Eliminato: (occasionally)

Eliminato: The role that the reference to causality plays in the connection between sensations and beliefs in his theory of interpretation is a deflationary one, since it aims to avoid epistemic intermediaries (e $g$., conceptual schemes) between the objects in the world and our beliefs (1983, p. 144) 
states, that we cannot "get outside our skins" to compare the worldly causes of our beliefs with the contents of our beliefs (1983, p. 144), one may wonder how we could get outside our skins to establish the nature of the dependence of our beliefs on the world and see that it is an instantiation of efficient causality.

If we look now at the connection between reasons (beliefs and desires) and actions as it is argued in "Agency" (1971), we can raise the same kind of doubt. Although Davidson introduces at a certain point the notion of agent causality (1971, p. 52), in the last instance reasons are said to be causes of actions in the ordinary sense of event causality. Davidson introduces the notion of agent causation because the ordinary notion of event causality is useful to explain "how agency can spread from primitive actions [...] but it cannot in the same way explain the basic sense of agency" (1971, p. 52). After introducing agent causation he specifies that "[w]hat distinguishes agent causation from ordinary causation is that no expansion into a tale of two events is possible, and no law lurks" (1971, p. 53).

The point that agent causation does not involve "a tale of two events" means, that when we describe actions we do not provide accounts of causal transmission as propagation between contiguous events: we extend the action unit to cover its "completion" (wherever we think that the pertinent completion lies). This descriptive peculiarity is termed "accordion effect", since the same action appears to be describable in shorter or longer units, according to the intended extension of the chain of consequences. The same action can be legitimately described by saying that I struck a ball with a bat or that (by doing so) I broke the window, but we would not accept the description "the bat broke the window": event causality propagates only contiguously.

Since agent causation is concerned with the effects (completion) of the act and since the choice of the relevant effects depends on our description of the event in intentional terms, Davidson can also make the point that "no law lurks": we are not in a position to produce predictive laws with reference to actions. Still, here we find an apparent contradiction between Davidson's claims, since he contends (NC) that "events related as cause and effect fall under strict deterministic laws", while he states, with reference to actions, that "we must appeal to the notion of cause when we lack detailed and accurate laws" (1980, p. 80), adding that, in this sense, "most, if not all, mental concepts are irreducibly causal" (2005, p. 216). How is it possible that causal interactions constitutively fall under strict laws, while actions described in causal terms express the lack of accurate laws? In fact, there is no contradiction since, as we said, we can ignore the underlying laws and still maintain that underlying laws there are. But this prompts us to pay attention to the real meaning of $\mathrm{NC}$, which implies that when we interpret actions in causal terms we are after laws that are presently lacking. Indeed, NC should be expressed in normative and dynamic terms, and not in static and descriptive ones. The true meaning of "events related as cause and effect fall under strict deterministic laws" should rather sound like "in the presence of some connections of events we are committed to describe them in causal terms, paving the way for our search for the most appropriate laws".
Eliminato: it is also true that it is not clear

Eliminato:

Eliminato: strictly speaking,

Eliminato: should not underplay the fact 
Of course, under this interpretation, Davidson's statement that causes and effects "fall under strict deterministic laws" is quite misleading, because they do not fall anywhere on their own. In this normative sense, the causal reading of a relation between events is just a preliminary step toward a possible (but not certain) upgrade of our knowledge through the discovery of laws, occasionally strict ones. When we deal with mental determinations, our commitment to the peculiarities of reasons and intentions overcomes our commitment to find strict laws; therefore we must stay at the level of causal relations without being able to reach the level of true explanatory laws. This reading is confirmed by the last pages of "Three Varieties of Knowledge" (1991), where Davidson writes that:

The normative and the causal properties of mental concepts are related. If we were to drop the normative aspect from psychological explanations, they would no longer serve the purposes they do. We have such a keen interest in the subject's reasons for acting and for his or her changes of belief that we are willing to settle for explanations that cannot be made to fit perfectly with the laws of physics. Physics, on the other hand, has as an aim laws that are as complete and precise as we can make them; a different aim (1991, p. 217).

In the end, the essential ground for the anomalism of the mental and the "heteronomic" character of the link between the mental and the physical seems to be traced back to the specific aims, or interests, that animate the production of interpretations in mental and physical terms respectively. Still, the privilege conferred to event causality in the explanation of action remains unjustified: it is clear that such privilege depends on event causality being interpreted as a neutral ground level, indifferent to descriptions in mental or physical terms. But this depends in turn on the alleged 'neutrality' of the notion of event, which is to be demonstrated,

(5) Davidson's notion of event has changed over time, from an early interpretation where events were identified by their causal relations $(1969, \mathrm{p}$. 179), to a later interpretation, explicitly inspired by Quine, where events are identified by their spatiotemporal coordinates (1985, p. 175). It must be noticed that initially Davidson had considered the latter solution and rejected it, because "if a metal ball becomes warmer during a certain minute, and during the same minute rotates through 35 degrees, must we say these are the same event?" (1969, p. 178). Apparently, two distinct changes (events) -- like warming and rotating -- can take place in the same place and time. Two main considerations tipped the balance in favour of the individuation of events in spatiotemporal terms. The first was that the initial proposal, by individuating events in terms of identity of causes and effects, had the apparent defect that causes and effects, being events themselves, made the definition circular. The second consideration was that in an ideal physical science instantiations of properties, like becoming warmer, could be fully reduced to sets of spatiotemporal events (the motion of particles within the heating sphere). In this sense, for a sufficiently fine-grained physical description, each moving

Eliminato: What remains obscure, however, is the

Eliminato: . It is clear from Davidson's account that he takes

Eliminato: to be

Eliminato: that we may then choose to describe

Eliminato: Yet it is doubtful that event causality can be regarded as a notion not compromised with physical accounts of the world, even if strict physical laws do not need to resort to causal terms. The question becomes even clearer if we take a look at Davidson's notion of "event". 
part of the mentioned metal sphere could be treated as a spatiotemporally individuated event. It seems, thus, that Davidson ends up by being committed to an understanding of events consistent with physicalistic accounts, such that events are (or are reducible to) point-instants

Davidson never explicitly states that events should be understood as point-instants, and actually, when he mentions events as experiential items it is clear that he does not have in mind the physicalistic idealization of pointinstants. However this difficulty can be set aside if we realize that for him "events have parts that are events" (1980, p. 83), and that, therefore, we can talk about events at different levels of elementariness. Only basic events must be understood as bare spatial-temporal coordinates (point-instants): they are unrepeatable particulars underlying various possible descriptions, but subsisting beyond all descriptions. Therefore, although one is not always required to talk of Davidson's events as point-instants, this acceptation is the most appropriate when dealing with the extensional nature of events underlying mental and physical descriptions.

This fluidity in the conceptualization of events reflects an original problem in the treatment of events. Events are primarily introduced as the common phenomenal basis that allows subjects to provide a plurality of descriptions: events are experiential particulars that can bear various descriptions. Yet, events understood as ideal physical determinations in space and time are not the same as events understood as experiential particulars. Actually, if events must really be bare particulars uncompromised with descriptions, then saying that their nature is spatiotemporal in the sense of physics seems to claim too much, since one can hardly maintain that determinations in spatiotemporal terms are not descriptions. This point must be emphasised in light of the fact that most of the charges of mental epiphenomenalism depend on the privileged position attributed to physical events. Davidson seems to say that events are what they are before and regardless of descriptions in mental or physical terms, but his argument in favour of monism demands that all events are physical, while not all events are mental (1970, p. 214).

In our previous interpretation, both $\mathrm{CI}$ and $\mathrm{NC}$ had to be read in the last instance in a normative frame: the Principle of Causal Interaction becomes something like "we are prone to explain some token causal interactions by describing causes and effects respectively in mental and physical terms," and the Principle of the Nomological Character of Causality translates into: "in the presence of some connections of events, we are committed to describing them in causal terms, in order to pave the way for our search for the most appropriate laws". Hence, the connection of CI and NC, so interpreted, implies that when we try to explain a connection of events in causal terms (which we are naturally prone to do), we are bound to look for strict laws, and this is true even when we are interested in a link between events respectively described in mental and physical terms. However, in this latter case our propensity to find strict laws is bound to be frustrated because of AM, which amounts to the fact that the concepts we use when we want to provide an account in mental terms are not compatible with the ones occurring in physical laws. Put in these terms, the argument sounds less intriguing than in the original version, but
Eliminato: is

Eliminato: Still,

Eliminato:

Eliminato: ever

Eliminato: 9

Eliminato: , instead of focussing on questions of semantics

Eliminato: the criticisms that raise the question of the

Eliminato: of the mental

Eliminato: are based

Eliminato: On the one hand,

Eliminato: any

Eliminato:

Eliminato:

Eliminato: ; on the other,

Eliminato: implies

Eliminato:

Eliminato: must be 
certainly much smoother. But what about monism? Can monism still be demonstrated in this new version?

It seems that it cannot be properly demonstrated, but that it must be assumed. In fact, in "Mental Events" Davidson argues in favour of monism on the basis of the fact that, whenever a mental event causes a physical event, under some description they instantiate a strict law, which can only be physical. And insofar as a mental event falls under a physical law, it is a physical event. "So every mental event that is causally related to a physical event is a physical event." (1970, p. 224) But in the normative interpretation the fact that a mental event is interpreted as causing a physical event does not imply that under some description this relation instantiates a strict law; it merely implies that we are committed to find such a law. Indeed, if we found one, we know that it would be a physical law (by definition), but there is no guarantee that there should ever be one. Consequently, the reasoning does not conclude that every mental event which is causally related to a physical event is a physical event in turn; rather, it amounts to saying that we are committed to read events in physical terms: we are "naturally" committed to physical monism. This is neither an uninteresting conclusion nor an uncontroversial one, but it is in any case a rather different thesis from the original one. If we try to make coherent the claims of $\mathrm{CI}$ and $\mathrm{NC}_{2}$ the result, far from supporting the epiphenomenalism of the mental, could even be read as a form of idealism (cf. Evnine 1991, pp. 155ff), since the role played by subjective interests and intersubjective agreement in descriptions seems to be overwhelming. However, it is also clear that Davidson himself is committed to a naturalistic framework, where events and causes are physical regardless of how they are described. It seems that in Davidson's approach there is a tension between a possible idealistic (or at least subjectivistic) reading and an explicit naturalistic commitment, while there are no conceptual resources capable of coping with that tension.

\section{Husserl on Events and Causes}

Edmund Husserl is another author whose work is permeated by a special tension between a possible idealistic reading and a peculiar attention to the commitment to naturalism. But Husserl is not himself committed to naturalism; on the contrary, naturalism is arguably his main critical object.

In his last published work, Die Krisis der Europäischen Wissenschaften und die transzendentale Phänomenologie (1936), Husserl shows how the project of naturalization emerges in Western thought as a correlate of the effort to mathematize Being. Physical nature is no physical fact, but a historical construct, which is not arbitrary but cannot be taken as an original source of evidence. In the Krisis Husserl argues that the life-world (Lebenswelt) is the dimension where we find the first sources of evidence on which all knowledge and science must rely. The life-world is organized in space and time, and it has a "causal style" before and regardless of any scientific conceptualization, while the naturalization of such pre-scientific notions corresponds to a peculiar mathematical idealization of phenomena (Hua VI, pp. 142-3, 221). Such a process of idealization grants full legitimacy
Eliminato: Let us recall Davidson"s reasoning

\section{Eliminato: :II}

The demonstration of identity follows easily. Suppose $m$, a mental event, caused $p$, a physical event; then, under some description $m$ and $p$ instantiate a strict law. This law can only be physical, according to the previous paragraph. But if $m$ falls under a physical law, it has a physical description; which is to say it is a physical event. An physical description; which is to say it is a physical event. An
analogous argument works when a physical event causes a mental event.

Eliminato: $\mathbb{q}$

Eliminato: We are prone to conclude

Eliminato: "

Eliminato: conceptuality 
to phenomena only insofar as they appear as subjectless objects, and therefore this theoretical move tends to supersede or miscognize all phenomena that do not fit in such an objectivistic frame. It is from this perspective that Husserl warns that biophysical reality can never be legitimately reduced to physical reality (Hua VI, p. 391), and that interpreting motivations as instances of physical causality is sheer nonsense (Hua VI, p. 480). These claims of irreducibility are not based on any dualist view of being, since dualism is explicitly rejected (Hua VI, p. 62). These late positions in Husserl's thought may suggest a kind of compatibility with anomalous monism, but we need to take a closer look at Husserlian phenomenology if we want to substantiate such claims.

In the previous pages we have raised doubts about Davidson's interpretation of events, which are the "atoms" of his ontology. We have now to notice that, from a Husserlian perspective, interpreting the most elementary constituents of ontology as spatiotemporal determinations in the physical sense is not one mistake among others but is more like the original sin of modern thought. To clarify this point we have, first, to recall that Husserl's phenomenological method aims to prevent hasty or dogmatic decisions concerning the ontological status of phenomena. Although epoché is a method rich in implications and aspects, its core is very simple: when we turn to any intentional content (i.e., to anything we can be conscious of), we must be wary not to decide in advance what its ontological status is; that is, we must suspend our judgment with reference to "reality" in a broad sense (Husserl speaks rather of Geltung, "validity"). We do not have to decide in advance what is essential and what contingent, what is actual and what delusional, what is objective and what subjective, and we do not have to grant any special privilege to specific categories or to a particular technical language.

The peculiarity of epoché in contrast to all past philosophical methods is that it does not aim to narrow down ab initio the range of legitimate starting points by claiming the privilege of a specific class of phenomena (e.g., percepts, clear and distinct ideas, etc.) or of a specific way to categorize them (e.g., neopositivist protocols). On the contrary, epoché is characterized by the effort not to outlaw any intentional content in advance. What we regard as delusions or mistakes can be part of our phenomenal basis no less than what we assume to be evident or apodictic: while describing them, we can mention in our description also our opinion about their ontological status (e.g., unreal, subjective, etc.), and this opinion will be substantiated or not by how the described phenomenon is correlated with other phenomena. What something is is determined by how it appears; being is a qualified subset of appearance. Incidentally, this perspective suggests that dealing with ontological issues as if they could be treated quite independently of epistemic issues is just a groundless philosophical attitude,

Yet, equating phenomena with appearance may mislead, since appearance is traditionally interpreted as subjective semblance. Thus, to say that being is a subset of appearance may sound like a vindication of absolute idealism, and Husserl's thought has often been accused of being an idealism akin to Berkeley's or Fichte's visions. However "appearance" (as well as "phenomenon") is just a name for experience in the most comprehensive
Eliminato: The question of what deserves to be considered a legitimate basis of ontology is probably the most thoroughly explored issue in Husserl's philosophical path, and to provide our discussion with a suitable basis we must provide a brief critical account of it. First we must recall

Eliminato:

Eliminato: Indeed, this is precisely the twin attitude of tackling objectivity while removing subjectivity, which is what naturalistic objectivism consists of. 
sense. Phenomenology can be understood as a radical form of empiricism, insofar as $\dot{\varepsilon} \mu \pi \varepsilon i p i ́ \alpha$ is any experience, and not just the specific way in which we experience through our sense-organs. In an important sense, everything that we experience is. Epoché brings to light the primal level of being, which is not reality yet but the field of all possible contents of experience. In order to determine what can be counted as reality, we have to look at the "way of givenness" (Gegebenheitsart), that is, at how phenomena are given to consciousness. Perception turns out to be the most original way in which contents are given to consciousness, since all other classes of phenomena -like recollections, expectations or fantasies -- intrinsically refer to the perceptual dimension, whereas perception can work without referring either to recollections, or expectations, or fantasies. Everything that is perceived is real in a sense (for which Husserl uses the term reell), but only percepts that preserve identity across a plurality of "adumbrations" (Abschattungen) are also real in the customary sense of existing in space, for which Husserl uses the term "real" (Hua III, § 41).

The fact that perception is the most original way of givenness, does not imply that perceptual objects are primal experiential elements. Perceptual objects are themselves constituted in a train of sensuous bodily acts unfolding "over time". To see a table involves direct access to a limited number of sensations: the visual ones that we gather in the focussed field seen from our perspective. Nevertheless, we perceive the table as a whole and as available from an indefinite plurality of points of view. The actual sensuous manifestation "adumbrates" the object as a whole, whose latent aspects are apperceived (apperzipiert). In this sense all perceptual objects are temporally constituted items, which presuppose a more originary dimension of experience. This originary dimension manifests itself as living present (lebendige Gegenwart), which is a unitary intentional pattern articulated into primal impression (Ur-impression), the retention (Retention) of just passed impressions and the anticipation of immediate impressional developments (Protention) (Hua Mat VIII, pp. 8ff). By primal impression Husserl means each present sensuous givenness that affects consciousness while being retained as constitutive of more and more complex experiences. Primal impression is how sensuous present is represented in the context of the temporal constitution of percepts, while our actually experienced present is never an isolated primal impression, but a living present.

Although no item in the Husserlian conceptuality quite corresponds to the Davidsonian notion of event, I believe that the notion of primal impression performs an analogous function of being the elementary constituent of ontology. Primal impression is the minimal anonymous "something" that must take place in order for all further qualifications of content to develop. If events, reduced to their core, are anonymous "changes" available for all kinds of further specification, primal impressions are events. Of course, primal impressions are also conceptually very different from Davidsonian events, but to reflect on these differences is instructive. To begin with, primal impressions cannot be said to be either subjective or objective, either passive or active, either real or unreal. When an anonymous particular change takes place for consciousness, consciousness is affected and reacts, and according to how the
Formattato: Tipo di carattere: (Predefinito) Times New Roman

Formattato: Tipo di carattere: (Predefinito) Times New

Roman 
chain of affections and reactions gets associated, intentional objects endowed with specific characteristics come to light. Neither primal impressions nor the way in which perceptual associations take shape are in the active power of the subject; however, they do not properly exist in the absence of subjectivity. We could say, with some approximation, that what originarily is takes place "between" subject and object. This way of expression is not fully correct, since it makes it seem that subject and object exist in themselves, with all their attributes, in advance of their "encounter", whereas really the most we can say is that "something" must have been there in advance. As to its possible articulations and attributes, nothing can be stated apart from that "encounter".

This original encounter finds its essential manifestation in what Husserl calls intentionality. All contents that we are going to attribute to subject and object, mind and matter, etc. are produced by peculiar sedimentations of experiences and therefore living experience is the primum from which subjective and objective predicates, mental and physical qualifications, progressively branch off. It must be noticed that, under these premises, monism of a kind is simply compulsory, Here monism is the only option because all determinations concerning substances and attributes are generated from a common source, living experience, which is a dimension posited beyond or before any distinction between an epistemic and an ontological sphere. Experiences (Erlebnisse) are not "in" the subject, because "consciousness is not a bag" (cf. Brough 2008), and the determinations of "spatial location" are constituted by intentional acts. This is no idealistic monism, since subjectivity (mind, consciousness) does not create being. Consciousness is not pure activity; it is equally reactivity and passivity (HuaMat VIII, p. 42). Still, consciousness can be never bypassed whenever Being is specified, regardless of how minimal the specification is; therefore materialistic monism is also ruled out: matter is already a specification to be motivated.

Husserl names "transcendence" (Transzendenz) the phenomenal dimension which is given to consciousness as "external" to consciousness, as being beyond (trans-) consciousness (Hua II, p. 72; HuaMat VIII, p. 52). What is transcendent is characterised by being experienced as an unexhausted source of information and therefore as something that we do not dominate. Husserl distinguishes different levels of transcendence. The most originary one is manifested by the way in which phenomena are originally given to subjectivity regardless of intersubjective relations: transcendence as it appears in the socalled primordial sphere (Hua I, p. 141). Although at the primordial level, without reference to intersubjective judgment, the subject is not in a position to grant objective existence to anything, this does not mean that everything appears as "dependent on me". Already at the original level of sensuous experience the subject experiences affections as something signalling irreducible alterity. As should be clear, the notion of transcendence captures the idea of being "external" to subjectivity without calling upon spatial determinations. On the one hand, when sensuous affections are primarily experienced they are not yet experienced as located in space, although such location is going to emerge when perceptual objects are constituted. On the other hand, objective entities that do not belong to the sensuous sphere (e.g.,

Eliminato: the
Eliminato: , aspects,
Eliminato: of such something
Eliminato: of
classical alternatives represented by materialistic and idealistic monism

Eliminato:

Eliminato: Let us now try to see how the "external world" is to be interpreted in Husserl"s conceptual framework.

Eliminato: , or may appear,

Eliminato: When, through the experience of other living bodies, we reach the experience of others as alter egos, a novel dimension of transcendence comes to the fore, since alter egos are not merely transcendent as original irreducible sources of affections but are also something that can objectify my very Self. Intersubjective ranscendence is therefore a qualitatively different sort of transcendence, which presupposes primordial transcendence (cf. Zahavi 1996, p. 27ff). When, after accessing intersubjective experience, we reach the dimension of objective judgments, transcendence can be also attributed to entities which are no longer ed to the perceptual sphere (e.g. mathematical truths), and this is still another level of transcendence. $\|$ 
essences) also manifest the character of transcendence (Hua II, pp. 9, 55ff.). What is transcendent is given as "external" to consciousness, but it is not "foreign" to consciousness; indeed, we have no right to express ourselves about something altogether foreign to consciousness, but we have sound experiential reasons to recognise items "external" to consciousness.

If transcendence is the dimension of what is "external" to consciousness, hyle is the term that Husserl uses to name matter as intentional correlate. The notion of hylé undergoes some changes over time, since the term is initially used as an equivalent of sensation a parte objecti, whereas it progressively assumes the further role of constituted substrate of all sensations. Thus the late Husserl speaks of an Empfindungshylé, which represents the basis for the apprehension of a naturale Hyle, which involves the sphere of perceptual objects in ordinary sense (HuaMat VIII, pp. 110-111). It is essential to observe that there is no room in this account for the ordinary notion of physical matter. Physical matter is ordinarily assumed to be a universal "substance," existing in space and time and devoid of any particular quality, while being the common substrate of all special qualitative determinations regardless of subjective contributions. But such an account is groundless, since no experience can ever support it. On the contrary, the nature of hylé, before any intentional specification, must be determined as the intentional correlate of sensuous experiences. Further spatial, temporal, and qualitative determinations require the contribution of (embodied) consciousness.

The Husserlian notion of Realität is of more relevance for confronting the extensionality of Davidson's spatiotemporal events. Husserl distinguishes in the semantic field of "reality" what is given as real from what is given as reell: all experiences exist as reell insofar as they are events in a temporally ordered stream, but only what we consider material nature exists as real, that is, it has both spatial and temporal identity; as Husserl writes at the beginning of Ideen II: "die Natur sei das Feld von transzendenten Realitäten, und zwar von räumlich-zeitlichen, (Hua IV, p. 1). This is precisely the representation of nature that is of concern with regard to naturalism. Realität is extensional matter as it is primarily given by the experience of transcendent percepts; it is primarily apprehended when we detect the unitary identity of a percept across changing sensations (Hua IV, p. 41). Realität emerges from the primordial sphere of experience, but this is not enough to fully characterize it, because Realität must also involve intersubjective agreement on its determinations (Hua IV, pp. 86-7): Realität is spatiotemporally determined in objective (intersubjective) space and objective (intersubjective) time.

Although Husserl's analyses of spatial and temporal constitution are so thorough that any resumé runs the risk of being gross and unfair, we need to give a cursory account of such constitution in order to proceed to the next stage of our argument. For Husserl, both spatial and temporal determinations are originally drawn from living relations involving embodied consciousness. Spatial determinations are originally drawn from perceptual correlations between our own perceiving body and the visual and tactual material surroundings: before becoming abstract spatiality available for physical specifications, space is primarily experienced as body-related coordinates such

Eliminato: $h$

Eliminato: any 
as up-down, left-right, before-behind. But when this experiential pattern has to gain intersubjective validity, all references to a specific body as a viewpoint from which all particular determinations are defined must be neutralized, and this leads to objective spatiality, which is propaedeutic to the introduction of abstract physical spatiality. As to temporality (to which we will return later), its core is represented by an immanent order of succession that can be determined only when consciousness "articulates" primal impressions into retentions and protentions. This implies that primarily any present is the living present relevant to an actually living subject, and that this is the divide that determines what is antecedent and what is successive in general. Again, if this early notion of temporality has to obtain intersubjective validation, then all particular references to actually living subjects and to their primal impressions must be suspended; to the extent that such suspension can take place, the temporality of consciousness becomes objective temporality as universal order of succession, which is preliminary to the constitution of abstract physical time. In order for both objective temporality and objective spatiality to become abstract physical representations a process of mathematical idealization must take place, where ordinal relations of juxtaposition and succession turn into numerically quantified relations.

This cursory account of the constitution of space and time must suffice for an analysis of the notion of event, which is at the core of Davidson's anomalous monism. From a Husserlian perspective, the naturalistic notion of event, far from being something simple and original, turns out to be the name of a multiply stratified construct, which constitutively refers to different layers of experience. Events are not ready-made spatiotemporal particulars available to be picked up by physical laws. The first layer of what are to become naturalistic events is provided by the manifestation of transcendence by perceptual experience; secondarily the perceived spatiotemporal transcendence must obtain objectivity through intersubjective recognition; and finally the mathematization of spatiality and temporality enables translation of what initially are just perceptual objects into anonymous numerically quantifiable determinations -- that is, into physical point-instants. From this genetic perspective on the constitution of events, we are thus in a position to provide a qualified reading of some of the difficulties inherent in the Davidsonian account.

(1) On the hiatus between the mental and the physical. As we noticed, Davidson's notion of mental events was circumscribed to propositional attitudes, and this was motivated by the fact that the argument for anomalous monism depends on the rational character of the mental. However, by depicting the dimension of the mental in these terms Davidson creates an inexplicable gap between the physical and the mental. While prima facie the relation between the physical and the mental is described by Davidson with reference to perception and action, in the end their interaction is read in the terms of abstract event causality. The abstract conceptual platform provided by event causality is justified by the extrinsic nature of the connection between the mental and the physical, which goes in parallel with the disregard for the analysis of experience (perceptual experience, to begin with). The hiatus between mental and physical accounts of events tends to split Davidson's

\section{Eliminato: further}

Eliminato: are transformed

Eliminato: and which, as we saw, is afflicted by a somewhat ambiguous status 
vision into a naturalistic dimension of physical events, where subjectivity as such is removed, and an "intersubjectivist" dimension concerning how events are described, where no transcendent constraint seems to be imposed on (inter)-subjective interpretation. In Husserlian terms, Davidson is not questioning the genesis either of physical reality or of intersubjective agreement, which are simply assumed without exploring their roots in subjective consciousness (with special reference to perceptual constitution). By examining how perceptual constitution is articulated into primal impressions, retentions and protentions, affections and hylé, transcendence and Realität, Husserl shows how the dimensions of the mental and the physical gradually branch out of a common origin.

(2) On the alleged ontological privilege of physical events. From a Husserlian point of view the ontological role played by physical events can be denounced as unwarranted. As we saw, Davidson considers physical events at two levels, as objects of physical descriptions and as core elements of ontology irrespective of any description. Being physical equates with being described in a physical vocabulary; however, events in themselves, irrespective of description, are understood as spatiotemporal particulars, that is, in the last instance, as physical point-instants. The privilege attributed to physical events has been variously criticized, but all criticisms are fruitless until it is shown why events should not be primarily conceived in physical terms. When we analyze events in the terms provided by the phenomenological constitution of Realität, we have a model where the original dimension of events is represented by an instance of anonymous sensuous "givenness" (primal impressions or kin notions), which is no more physical than mental, that is, is lacking all determinations that could support mental or physical descriptions. This implies also the lack of all spatial and temporal determinations. In this framework, physical events have no privilege and there is no reason to support the thesis that "all mental events are physical, but not all physical events are mental". This thesis cannot rely on the alleged fact that "all events described in mental terms can be described in physical terms, whereas not all events described in physical terms could be described in mental terms". Indeed, this is patently false, since we can describe in mental terms all events described in physical terms. It would be strange indeed if the content of a description (physical ones included), which is a mental event in any possible acceptation of the mental, could not be described also in mental terms. The only thing that can be granted is that all events (instances of anonymous sensuous "givenness") can receive a physical description as well as a mental one.

(3) On the alleged ontological privilege of event causality. The most important change of perspective that we must note concerns the relationship between events and causation. In the Davidsonian account of events it is not clear how causal powers could ever be attributed to spatiotemporal particulars. We are told that events causally interact regardless of how they are described, however events understood as physical point-instants do not seem to leave room for "efficaciousness". In fact, Davidson's notion of event seems to define more an ideal object than an event, and it is awkward to say that a point or a collection of points in space and time exercises "causal power" on other

Eliminato: If, more simply, the idea is that "intuitively" all event events are neither physical nor mental, and we are now in a position to show in which sense. 
points. Since properties are something that must be attributed to events by descriptions, we are invited to conceive of causality as a relationship between events regardless of their properties, but such event-causality does not account well for the efficaciousness of causes. And indeed, Davidson does not focus on the efficaciousness of causality, but only on its law-like aspects; this is what is implied by the principle of the nomological character of causality. The point of being a cause is no longer to "make things happen" but to fit in universally quantified statements supporting counterfactuals and leading to forecasts. But by interpreting causality in terms of strict physical laws we subject the notion of cause to a theoretical metamorphosis, where the aspects that fit into laws (positions in time and space) gain the upper hand, while efficaciousness (force, power, resistance) appears as secondary or irrelevant. As Davidson himself recalls, this is indeed how physics treats causality, which is expunged from the formulation of physical laws. In the Husserlian framework, on the contrary, events are naturally efficacious since they are constitutively affecting. It seems that we have come to a point where causality is suspended between an account in terms of laws, which stresses on positions in space and time, and an account that focuses on efficaciousness, where spatial and temporal determinations are a late result of constitution. At this point, our discussion has progressed enough to tackle its main object: we must understand how causation is to be properly understood if we want to gain a picture where anomalous monism (of a sort) is in place, without running the risk of epiphenomenalism, that is, without making out of mental causation an enigma or an illusion.

\section{Consciousness and causality}

Husserl intensively deals with the relationship between consciousness and causality in Ideen II, and it does not seem that his opinions on this question significantly change in later works. For Husserl, Realität and Kausalität belong together; they are both notions that emerge from the constitution of things, which presupposes perceptual activity and the constitution of objective (intersubjective) space and time. Real (real) qualities are constitutively causal; to know a thing means to have knowledge, consistent with experience, about how the thing behaves when it is pushed, pressed, bent, heated, etc. (Hua IV, p. 45)

Now, we have seen how efficaciousness can be primarily recognized in events (as primal impressions, or kin notions), but it is not immediately clear how such efficaciousness should be represented in order to become causality proper. One thing is the idea of the experience of something transcendent that affects me; quite another thing is the idea of a general power to produce affections, regardless of the presence of actual consciousness. True enough, we can straightforwardly conceive of an event taking place without any present consciousness to the extent that we determine such an event in terms that make implicit reference to a possible instantiation of consciousness: roses are still red when nobody looks at them, because we attribute the properties that they would manifest if somebody looked at them. But is there a similar straightforward way to make experienced efficaciousness independent of the

Eliminato: . In other words, we want to see whether the phenomenological conceptuality allows us to draw a picture of causality which does not make 
actual availability of consciousness? And would this objectified efficaciousness be equivalent to ordinary causality? In fact, causality is a complex notion and we need to disentangle its constitution before trying to see if and how causality can be understood as objectified efficaciousness.

Husserl does not really produce such an analysis, although his general vision is rather clear: causality in the sense in which we use the term with reference to natural processes is not a concept whose validity can be extended without limits to all ontological regions. The causality pertinent to acting subjects is not the causality of nature (Hua VI, p. 222), and in this sense it is wrong to refer to the workings of the soul (Seele) in terms of causality (Hua IV, p. 132) When we have to do with events that appear to exercise their efficaciousness on the way we are conscious of things -- for instance when we are administered a psychotropic drug -- this kind of "psychophysical causality" is not termed causality, but "conditionality" (Konditionalität), and the effects that we may experience at the level of perception or judgment are not to be understood as effects of causes in the ordinary sense of natural causality (Hua IV, p. 64; Hua VI, p. 248). The point is that what happens in the sphere of consciousness follows the logic of motivation (Motivation) and not of efficient causality, and this implies that all events of which we are conscious take place in a framework determined by intentional relations and are irreducible to extrinsic causes. Still, it does not seem that Husserl arrives at a wholly satisfactory view of the relationship between consciousness and motivation on the one hand, and reality and causality on the other. What is clear is that motivation and natural causality are two distinct and incompatible ways to describe events, much like mental and physical descriptions are in Davidson. Where Davidson says that the logic of mental events is such that beliefs can be supported or refuted only by further beliefs, Husserl shows that all connections between events of which we are conscious are defined by intentional relations. In both cases it is nonsensical to interpret the workings of the mind (or of consciousness as such) in mere causal terms, and this supports the 'anomalousness' of the relation between mental and physical descriptions,

However, while Davidson in the last instance shows an unjustified ontological partiality towards physical events, Husserl's conceptuality does not provide any symmetrical partiality towards "mental events", which would spell absolute idealism. The priority of consciousness is ontological priority only in a special sense, because it concerns the determinations of Being, not its creation. This implies that motivation, which is the principle that rules over conscious relations, does not obliterate the primal efficaciousness that is manifested in sensuous transcendence. This leaves open the question of the relationship between the sphere of intentional relations (motivations) and primal ontological efficaciousness. How is such primal ontological efficaciousness to be interpreted, if we have to refrain from equating it either with causality or with motivation? In Ideen II Husserl's last word about this question seems to be an argument via negationis: he recalls the naturalistic position, according to which mental causality seems to be a fact, but an incomprehensible one that is therefore continuously under threat to be regarded as mere appearance (bloßen Schein). Then, however, Husserl concludes that such an "enigma" (Rätsel) belongs to the essence of causation

Eliminato: : "Nicht jede gesetzlich geregelte Funktionalität in der Sphäre der Tatsachen ist Kausalität." 
as such, and that consequently mental causation is no more an enigma than is causation in general (Hua IV, pp. 259-260). It seems thus that from a Husserlian perspective we should treat true ontological efficaciousness in somewhat agnostic terms. But this answer is at least partly unsatisfactory, because Husserl has not shown how ordinary efficient causation is to be regarded as an enigma. It is not enough to rely on Hume's famous criticism; one must display the limits of efficient causality through a phenomenological account of its constitutive conceptual layers, a task we shall pursue in the remaining pages.

In order to outline such analysis, let us consider what appear to be the essential constituents of our ordinary understanding of causality. Prima facie we would list four such constituents: efficient causality is supposed $\alpha$ ) to take place between well-determined events, $\beta$ ) to propagate in a contiguous way, $\gamma$ ) to follow the temporal order according to which antecedents cause successors and $\delta$ ) to be efficacious (to make things happen). We will not argue for the exhaustiveness of this articulation, but we believe that it characterizes the common notion of causality and will try to provide a genetic analysis of each constituent.

( $\alpha$ ) Well-determined events. Efficient event causality is something that is meant to take place between well-determined events: events that are ideally circumscribable in space and time cause other ideally circumscribable events. Complex "fuzzy" interactions are supposed to be the sum of linear ones connecting well-determined events. However, this is neither a priori evident nor actually true to experience. Whenever we reflectively dwell on a causal process we easily realize (a) that beginning and end of a causal process are chosen according to our driving interests and do not mirror the intrinsic course of a causal sequence, which appears to be intrinsically endless; (b) that the "causal line" that neatly connects two events is always necessarily surrounded by "side-effects", which are unintended or uninteresting implications. The reason why these two objective aspects of efficient causality are disregarded is not itself something "caused by facts", but belongs to the sphere of motivation. When we conceive of a specific event as a cause, we give a specific privilege to it: it becomes the active side in a correlation where in fact nothing is, objectively considered, either simply active or passive. The premise for something to be active is that it is an irreducible starting point; otherwise it would be understood as a passive transmitter of a previous impulse. But clearly nothing can be posited as an irreducible origin at the level of efficient event causality. As von Wright argued, at the phenomenal level we have at most constant successions, but even if we found a perfectly regular string of identical events, we would be never entitled to say that the antecedent (A) in the regular sequence causes the constantly associated follower (B). This is the case because any constant succession of two elements could be alternatively explained by an indefinite third causal factor (C) antecedent to both A and B and producing them separately (von Wright 1971, pp. 73-4), without them directly connecting at all.

Von Wright rightly concluded that causality is not understandable without reference to the notion of action, which names the actual efficaciousness of an event on another and not just their constant association. 
If we really want to "purify" causality from all intentional contributions, we should make an effort to conceive of causality as continuous endless and directionless efficacy. Causality in itself, whatever it may be, cannot have points of origin; causal sequences do not begin, do not end, and do not go in a single direction; only if and when events are actively circumscribed by us do origins, ends, and directions begin to emerge. When physical experiments are performed, we look for specific repeatable connections and are ready to grant that not all causally relevant variables are under our control, provided that they can be regarded as uninfluential for our concerns. This is of course the only sensible procedure from the point of view of our anthropic interests, but we should not fall prey to the illusion that we therefore somehow know that causality is intrinsically articulated into a finite number of ordered sequences of events, which we could in principle, if not in practice, exhaustively list and dominate. Such alleged finite list is an ideal product of our efforts to put order in the world of experience,

Indeed, there is no originating event in the first place, not only because the sequence of causes has no origin, but because "objectively" events have no specifiable boundaries. When we conceive of events as if they were pointinstants, we ideally eliminate the problem of the ontological identity of the real event by substituting the procedure of identification for its content: events become the coordinates that allow us to identify events. But a point-instant is an ideal entity to which no actual causal power can be attributed. On the other hand, if we wanted to fill the notion of event with empirical content, we should talk of a process unit lacking intrinsic boundaries, because there is no intrinsic boundary between what happens and what is caused to happen. Just as we cannot objectively delimit the range of causes and effects intersecting in an instantiation of causality, so we cannot objectively say where an event is exhausted and another one begins. We can and do determine events, but there is no such a thing as an intrinsically well-determined event.

( $\beta$ ) Contiguity. This leads us to the classical question of the contiguity of effects. As we saw, Davidson noticed that the causal powers pertinent to agents are described in terms that go beyond strict contiguity, allowing the accordion effect. Put in these terms, it seems that strict contiguity in the propagation of effects is the objective rule of which effects at a distance are the subjective exception. I can be said to break the window by swinging the bat and hitting the ball, while the bat is not said to break the window, but to produce a sequence of contiguously propagating causes that involve, among other things, the breaking of the window. Indeed, from a naturalistic point of view there seems to be a strong propensity towards conceiving causal relations between events as constitutively contiguous, even when no intermediate links between cause and effect are manifest. This is apparent if we think of the approach of field physics: for instance, when we describe how an electromagnetic field operates, we describe it as if it contiguously affected what otherwise would appear as something influenced at a distance. The concept of field transforms an apparent effect at a distance into a contiguous effect (cf. Bunge 2009, p. 60).

However, granted that there may be good reasons for setting physical causation in a framework of contiguous interactions, what is the actual role of

Eliminato: Although Davidson does not commit himself to a precise position on the contiguous nature of event causality, he does contrast the description of the propagation of effects for agents and events respectively along the lines of action at a distance versus contiguity. And i 
contiguity in causality? The first thing that we have to observe is that strict contiguity ideally involves absolute proximity, but absolute proximity is an idealization and does not tolerate any distance. Therefore, if we should be faithful to causal propagation by strict contiguity we would be never able to conceive of any propagation at all. As in Zeno's paradoxes, the ideal nature of events conceived as ideal point-instants leads to the inconceivability of motion (here of propagation). Let us suppose that event A should contiguously cause event $B$; if event $A$ is located in point $\alpha$, and event $B$ in point $\beta$, different from $\alpha$, then the propagation of causality from $\alpha$ to $\beta$ is propagation at a distance, because however close we take $\alpha$ and $\beta$, there will be always infinite points between them. If there were no points between $\alpha$ and $\beta$, they would be the same spatiotemporal determination and no propagation would take place. This means that, conceptually speaking, causal propagation cannot but involve a distance, i.e. a spatial difference, between causing events and caused ones. Therefore contiguity is not just extrinsic to the essence of causality, as Mario Bunge has shown (Bunge 2009, p. 62), but is even inconsistent with the very idea of causal propagation. The claim that causation operates by contiguity does not rely on empirical facts, but is an ideal demand iterable on any causal link.

But if contiguity is a demand that we are prone to impose on causal accounts, what is the nature of such a demand? We demand that attention be primarily paid to the relatively closer events in each chain of causal propagation. But why do we do so? We do so because, when we isolate a causal chain, we identify an effect as terminus ad quem of the sequence according to our salient interests. Once the end is identified, our interest goes to the means that are supposed to lead to that end; therefore, we are concerned in principle with all the intermediate steps leading to the interesting end. In this framework our focus on contiguity in the propagation of causes consistently follows our interest for the "means" leading to the "end". But then we should say, with Davidson, that the styles of causal propagation concerning event causality and agent causation are indeed different, but against Davidson, that the intentional character of agent causation pertains also to event causality. The descriptions of causal propagation in noncontiguous terms that Davidson admits only for agent causation (accordion effect) cannot be bypassed when we deal with event causality. Agency is decisively present in our descriptions of efficient event causality; and contiguity, far from being an intrinsic feature of causes, is an ideal demand imposed on causal accounts in order to investigate causes as possible means to ends. The focus of efficient causality on the relatively closer steps is relative to the identification of a causal unit with a beginning and an end, which is possible only by descriptions in agential terms (as in the accordion effect),

$(\gamma)$ Temporal order. In fact, spatial contiguity in the propagation of causes can also be read as a correlate of temporal succession. Since causes unfold by following a temporal order where the antecedent immediately affects the subsequent, the propagation of effects must follow a spatial order where the antecedent contiguously affects the subsequent. But, although we may be ready to grant the highest degree of certainty to the order of succession that characterizes ordinary efficient causation, we have to realize that such
Eliminato: Is contiguity intrinsically inherent in causality? And if not, why does contiguity usually play such a prominent role?

Eliminato: One might object that this is true only for strict idea contiguity and not for the kind of contiguity that we continuously experience in efficacious connections. However, this objection misses the point of the demand for contiguity: $t$

Eliminato: is

Eliminato: that can be iterated

Eliminato: e-effect

Eliminato: , like the ones supporting the accordion effect 
order is no more intrinsic to causation than the pattern of contiguous propagation (cf. Bunge 2009, p. 63ff.).

Still, we are not just interested in seeing whether temporality and causation are intrinsically or extrinsically connected; we want to understand what the nature of this connection is. The Husserlian reflection on time and consciousness has been highly influential and is rather well-known; nevertheless, I think that its implications for the issue of mental causation have not yet been fully appreciated. Husserl observes that our ability to conceive of the past and the future presupposes an immanent associative dimension which produces the very unfolding "strings" of events that we resort to in our reflexive apprehension of time. "Retention" is the train of impressions that is retained in consciousness whenever we are engaged in intentional acts, and this allows us to interpret events as elements in an unfolding pattern. We could never hear a piece of music as such if our hearing were tied to the instantaneous presence of the sound, but retentions allow us to understand a musical note as "coming from the preceding ones". Retentions are given to thematic consciousness only secondarily, by a reflective act, but primarily they have a "latent" unthematic nature. This is the case for protentions as well, which, however, are given to consciousness in a characteristically different way. Protentions are on display when we are surprised by something, even if we did not consciously expect anything; in these cases we realize that an immediate tacit expectation was latently at work. Strictly speaking, neither are retentions properly past nor protentions properly future, since they are the experiential premises for the constitution of full-fledged past and future, which require the ability to recognize events in an objective (intersubjectively valid) order of succession.

Now, a superficial reading of Husserl's pages on inner timeconsciousness -- especially when it is limited to the 1905 lectures -- can lead to psychologistic interpretations where retention and protention are understood as psychological faculties. For example, retention may be interpreted as just another name for short-term memory. This approach deprives Husserl's reflection on time of its ontological grip. When Husserl speaks about the constitution of temporality, he is not speaking metaphorically, as if the point was to make out the "mere consciousness" of temporality, while temporality in itself would lie somewhere else, untouched by the fate of consciousness. The core of temporality is provided by the order of succession of events, and such order is conceivable only insofar as there is a constituting consciousness (which is not a physical brain),

This point can be best understood if we reflect on the nature of our representation of the physical. Let us suppose that we assume that there is an intrinsic order of succession in nature, which must be merely recorded by consciousness but which does not need any consciousness to be in place. Yet, is there anything described in terms of pure physical matter that can account for the establishment of an order of succession? Let us imagine that a meteorite travels in a subjectless universe and hits "over time" various minor heavenly bodies; and then let us ask where, at any point, the bygone succession of collisions is to be found. An ideal physical description can give us at most a finite amount of signs or traces left on the present meteorite by the 
collisions, with the proviso that they cannot be really interpreted as signs or traces. In fact, all we ideally have is a present snapshot of the physical state of the meteorite, where nothing intrinsically expresses the fact that some present configurations of the meteorite refer to its past collisions. The surface of the meteorite would be like an impressed film where all impressions have taken place on the same photogram: nothing can tell us what the order of succession of the impressions was. Actually, even if we had a footage of the history of collisions of the meteorite, in the absence of an instantiation of consciousness this would be just another present piece of matter (an exposed photographic film), which does not bear the slightest intrinsic reference to any order of succession of events. To become indicative of an order of succession the film must be read, and this reading cannot be performed by further physical states of affairs, but requires consciousness.

The point is that no present amount of physical matter, whatever its configuration, can be conceived as repository of an order of succession: not the surface of the meteorite, not a filmed record, and not even a cerebral state. Merely present events must become part of a living present in order to become signs or traces of something, and in order to become patterns of events ordered in a succession. This implies, among other things, that temporality in itself requires consciousness, i.e., that there is no temporality in the absence of consciousness. The living present retains the just gone events in sight of the coming ones, and expects specific events to come in the wake of the retained ones. This living process weaves together events as experiences and thus constitutes meaningful units unfolding "over time".

However, to understand the ontological implications of this view of temporality is far from easy and directly involves the relationship between time and causality. Indeed, one could wonder if, by tracing temporality back to consciousness, we are not just slipping into absolute idealism. But this is not the case, since we are not saying that consciousness creates all events, but only that it establishes their order of succession, which must be therefore understood as something that does not intrinsically belong to "nature in itself". Still, somebody might object that we have at most shown that consciousness is the only "thing" that can discover and properly record successions: successions should be taken to exist in themselves in order for consciousness to detect them. However, the fact that successions are "discovered" and not created does not imply that events intrinsically unfold in objective successions. They "unfold" insofar as they take place as phenomena, which call upon subjectivity. Actually, in the absence of subjectivity there are no proper events, although we have reason to grant that "something exists in itself". No order of spatial coexistence or temporal succession can be granted in a subjectless world -- therefore no forms, structures, configurations, units, no unitary things and no oriented motions. The claims about "nature in itself" that phenomenological experience can justify are just the independent subsistence of "something" and the independent occurrence of "changes".

It is undoubtedly hard to conceive such a subjectless universe, since everything we can imagine is bound to appear as a structured unit located in subject-relative space and time. Still, if we realize that both coexistence and succession are relative to a living viewpoint, we can "represent" via negationis

Eliminato: More radic

Eliminato: $\mathrm{n}$ actual 
a universe where neither coexistences nor successions are recognizable options. In the absence of any point of view and of any privileged medium of apprehension (e.g., sight), we realize that all possible entities lose their unity and their identity; we can assume that the units that we actually identify are carved out from an infinite patternless "stuff" according to a point of view and a privileged medium of apprehension. All events, all things and all processes appear to exist as selections brought to light by consciousness when dealing with alterity. But "selection" here must not be understood as if it were the circumscription of a particular in a larger picture, because this interpretation would imply that our awareness of reality is just quantitatively limited, but that it can be exhaustively faithful to nature within those quantitative limits. Consciousness "selects" in a radical sense, involving the way in which objects and all their attributes are given.

Should we dare to provide an image of this sense of "selection" by consciousness, we would resort to the following (old-fashioned) analogy. As the world given to our sight and the world given to our smell give us incommensurable attributes resting on the same ontological basis, and as neither class of attributes can by itself reveal the existence of the other, analogously we should try to conceive of our world as "existing" in the "same space and time" simultaneously with an indefinite number of "other worlds" that we are not in a position to recognize (and that, therefore, can be only improperly called "worlds"). Such worlds could in principle interfere with our world, even if no "logic" could be recognized in such possible interferences. Thus, for instance, if there were "impulses" transmitted at infinite speed (which cannot be excluded either logically or empirically), they could not be said to propagate through space and time, and therefore they could never be recognized as causal processes, although they could interfere with, or even incognito permeate, our world. What we must conclude is that causation as efficaciousness (as in the above mentioned "interferences") and its temporal order are totally independent phenomenal dimensions.

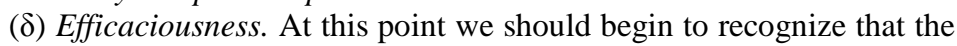
transcendent (intrinsic) core of causality is represented by efficaciousness alone, which is not constitutively tied to any specific way to "transmit" it (cf. Cartwright 2004). We are justified in granting that at the core of what we call causality there is intrinsic efficaciousness: "things" happen and are made happen regardless of consciousness. But when we further assume that causality unfolds between well-determined events, by contiguous intermediate steps and in a temporal order, we introduce traits that depend on how experiences are given to consciousness. This, we insist, does not mean that these traits of efficient event causality are somehow "delusional" or "fallacious" but defines the appropriate explanatory level at which efficient causality can operate: only in a world where subjectivity and agency are originally given there is room for ordinarily understood efficient causality.

When saying that efficaciousness lies at the core of causality, we must be wary to refrain from any naturalistic reading of efficaciousness. For instance, we have to reject any attempt to account for efficaciousness in terms of physical notions like the conservation laws (Dowe 2000, Salmon 1998). Indeed, it must be noticed that we can preserve our understanding of 
efficaciousness even if we imagine that conservation laws are violated. Even if part of the inertial momentum in the notorious clash of Humean billiard balls would get inexplicably lost, we would not deny that the first ball has been efficacious on the second. Furthermore, we cannot use the empirical instantiations of any conservation law to define the nature of efficaciousness, since our organization of physical experiments and empirical investigations presupposes a preliminary grasp of efficaciousness, which need not refer to any physical theory. Thus, even if we believed that conservation laws are the correct physical representation, of causality, efficaciousness must be discussable without reference to it,

A genetic constitution of causality, as far as we have reconstructed it, shows that efficaciousness is originally experienced as sensuous transcendence, primarily at the level of primal impressions. At this level, which is the one where we have identified the appropriate room for events as anonymous particulars, there is no active-passive divide yet. When percepts are constituted, the recognition of a last irreducible dimension of objectual efficaciousness consolidates. And when agency and objects are constituted, if we try to grasp the originally alien dimension of efficaciousness, we do it by articulating experienced reality into events connected by causes, where conceiving of a causing event is tantamount to conceiving of an intervening agent. This is the level of description where efficient causality proper is in place, with its reference to well-determined events that act on other welldetermined events by contiguous stages, where antecedents cause successors. Once efficient causation is constituted, we can successfully apply its descriptive model to manifold explanations, but the only explanatory act that is a priori forbidden is the conceptual reduction of agency and subjectivity to efficient causality, because the constitution of efficient causality presupposes the efficacy of "agent causation". Now we are in a position to fully understand why, as Husserl put it, "Motivation als eine Art Kausalität ansehen [...] ist widersinnig" (Hua VI, p. 480). And it should become equally clear why mental events cannot be reduced in any sense to physical events, even if we accept a monistic ontological framework.

\section{Conclusions on mental causation and anomalous monism}

(1) Monism. Monism is supported by the ubiquity of efficaciousness as far as efficaciousness is given to consciousness. No articulation of our world, regardless of how abstract or ideal, can be said to exist in a dimension foreign to efficaciousness of a kind. This does not mean that we have to make out where "thoughts cause things", because efficaciousness is not causality. The point is that nothing that we can think can possibly belong to an altogether separate ontological sphere, precisely because we can actually think of it, and this is already a mental change which has the power to affect bodily changes and to be affected by transcendent events. The ubiquity of efficaciousness is warranted by the fact that all phenomena can affect and be affected by all other phenomena, since consciousness guarantees the interaction of all phenomena, Such interaction has motivational and not causal character: while

Eliminato: . This means that

Eliminato: , which are phenomena to the extent that they are given to consciousness

Eliminato: . W 
there are connections that we cannot describe in causal terms, all connections can be described in motivational terms.

When Davidson stated that mental events causally interact with physical events, only to conclude later that we cannot rationally describe how they are causally connected, he was saying in fact that mental and physical events are motivationally connected, whereas we do not have enough determinations to establish causal connections. Instead of saying that physical events (through sensations) cause changes of beliefs, but do not justify them, he should have said that physical events as sensations motivate changes of beliefs and that when we describe such motivation in causal terms we lose those motivational aspects able to justify the change of belief. Similarly, instead of saying that beliefs and desires cause actions, even if we do not know how, he should have said that actions are motivated by beliefs and desires, and that when we want to describe such motivational connection in causal terms we lose the "connective tissue" that keeps together mental and physical events.

To be clear, the ubiquity of efficaciousness that supports monism is not the ubiquity of objective efficaciousness: we do not know and cannot know whether everything that in some sense exists can act on everything else. What we do know is that all instances of efficaciousness given to consciousness are motivating, and therefore they are constitutively tied together at the motivational level. When we describe such efficaciousness in the terms of efficient causality, we try to apply to the motivational presuppositions for the subsistence of events (or objects) an explanatory key born to be applied to events (or objects). This operation is constitutively misleading, because efficient causality is the form that efficaciousness takes when agents articulate experienced processes into ends and means. Efficient causality makes sense only when a "meaningful orientation" of life is already given.

(2) Final and efficient causes. It is a mistake to think of final causes as an explanatory alternative to efficient causes, because finality and efficiency are complementary, not alternative notions. On the one hand, efficient causality cannot be conceived at all without a motivational dimension (agency), which posits an interesting beginning of causation and is "stretched forth" (protentions, expectations) towards the relevant effects. However, on the other hand, we cannot conceive of ends exercising any direct causal power from the future. Apart from the logical paradoxes that can be easily produced if we assume that the future can causally affect the present (cf. Black 1956), the point is that we simply cannot make sense of an end that is causally effective without resorting to efficient causality. Yet, efficient causality is not conceptually self-sufficient in order to account for ontological efficaciousness. Final causes cannot bypass efficient ones because the motivational dimension has an unreal (non-actual) status, in the sense that it does not belong to the sphere of existing things: we are motivated by latent items, by desired situations, by open possibilities (also the "will to survive" is such a motivation). In order to see how something is caused in spatiotemporal reality we have to anchor causality in a present state of affairs and this excludes the motivational sphere as such from being directly a causal power. But such anchoring in present states of affairs is required by an essential motivational instance: the present is constitutively the dimension where we are active, and

Eliminato: as we said 
precisely where we are active in the wake of the past and in sight of the future. From this point of view causal power can be attributed indeed only to what is from time to time the present; and such attribution is grounded in the motivational dimension. Whenever we try to imagine that past or future have autonomous causal power we posit them as present "somewhere" (for instance, as produced configurations of matter or traces in the brain). Thus, it is pointless to make efforts to imagine how the past as past or the future as future could be causally efficacious, because this can be done only at the price of denying the non-actual nature of past and future. The efficaciousness of the non-actual dimensions of past and future is not the efficaciousness of causes, but is attested by the fact that consciousness posits the privilege of actuality for efficient causality,

The notion of final cause is a spurious one and must not be used to argue for the efficaciousness of the motivational sphere. The motivational sphere is to be regarded as efficacious a fortiori insofar as ordinary causality (with particular reference to temporal order) is considered to be real. The price to pay for asserting the epiphenomenalism of consciousness would be to reduce spatial locations, temporal dimensions, and circumscribable events to illusions; and this would dissolve efficient causality itself.

Objectivism dogmatically assumes the opposition between the epistemic and ontological dimensions as a severance between what is given to the subject and what intrinsically exists. From a phenomenological perspective this opposition is not an assumption, but the outcome of an analysis of experience, and its scope is strictly circumscribed. Efficaciousness, but not full-fledged causality can be attributed to a subjectless ontology. Causality is an essential part of our view of reality, and if we want to preserve it we have to preserve phenomena (temporal succession, to begin with), which is possible only if we grant efficaciousness to consciousness. Motivation cannot be found anywhere in nature because it is at work everywhere, but it is not at work as an instance of efficient causation, is no circumscribed spatiotemporal unit. Strictly speaking, there is no such thing as "mental causation", but the efficaciousness of the motivational sphere is at least as indubitable as the reality of event causation.

(3) Laws and anomalism. If monism is supported by the ubiquity of efficaciousness, the anomalous nature of this monism can be derived from the fact that laws of nature and efficaciousness do not belong to the same phenomenal sphere. The traits of causality that allow us to construct physical laws endowed with predictive powers $(\alpha, \beta, \gamma)$ are not the same traits that make us say that there is a transcendent dimension of events, or, that there are events regardless of how they are described $(\delta)$.

As we saw, Davidson argues that mental events and physical events cannot be equally described by strict laws because our interests are differently laid: holistic and normative traits would be our concern in the mental sphere, while the closure of the physical realm would be our concern with regard to physical events. However, Davidson invites us to conceive of the mental and the physical as two spheres lying side by side at the same level. Then, since the sphere of the mental is conceived in the form of events, we are called to wonder how such a peculiar sort of events could interact with physical events,

\begin{tabular}{l} 
Eliminato: straightforwardly \\
Eliminato: the non-bypassability of \\
Eliminato: , which determines \\
motivational dimension of consciousness must be recognized as $a$ \\
fortiori efficacious \\
\hline Eliminato: its use \\
\hline Eliminato: is mistaken \\
\hline Eliminato: : $t$ \\
\hline Eliminato: of course, \\
Elimininato:, \\
\hline
\end{tabular}


and this readily paves the road to epiphenomenalism. But phenomenologically we should keep neatly separate two conceptual couples, which operate on different planes. One thing is the opposition of the mental and the physical at the level of events (in the third person), quite another is the opposition between constituting consciousness and transcendence (in the first person). Efficaciousness is originally experienced at the level of primal impressions, when hylé gets constituted and transcendent traits emerge. Efficaciousness is therefore a feature of causality which is co-original with consciousness and subsists regardless of the determination of events.

While efficaciousness is not constituted by consciousness, events as spatiotemporal determinations are constituted: $\alpha, \beta$ and $\gamma$ depend on consciousness and on the motivational sphere. But such spatiotemporal determinations are also precisely those features of ordinary efficient causality which, once quantified, enter into physical laws. This means that physical laws are never in a position to capture consciousness and motivation. However, this does not say anything yet about the relationship between physical laws and mental events, especially because the very status of mental events as objective states of affairs is ambiguous.

"Mental" cannot be just synonym of "pertinent to consciousness", because otherwise all events, also physical ones, should count as mental, since they are all constitutively pertinent to consciousness (in the first person). By mental events we might mean psychological phenomena, which are given, only in the third person, when we identify manifestations of subjectivity in others. Here $_{\text {it }}$ is possible either to focus (1) on the manifestations of subjectivity, stressing on the unity of consciousness as far as we recognize it in others' bodily expressions, or (2) on the manifestations of subjectivity, focusing on specific bodily functions, connected with consciousness, but investigable in isolation (cerebral, neurophysiological and cognitive functions). Mental events are anomalous only in the first acceptation, which emphasizes the mental character of mental events, but not in the second, which emphasizes the eventlike character of mental events. The impossibility of subsuming mental events under strict laws depends on the fact that we treat "mental events" as manifestations of a unitary subjectivity, i.e. of an embodied instantiation of consciousness. From this perspective mental events can be regarded as "anomalous" insofar as consciousness is anomalous, and consciousness is anomalous because it is the presupposition of any law.

To the extent that mental events are expressions of unitary subjectivity, the normative and holistic characters that Davidson mentions are pertinent. But in this sense the objective spatiotemporal determinations of mental events are completely irrelevant to their nature, in the same sense in which the fact that they are constituted by consciousness is irrelevant to the nature of physical events and physical laws. Essential to "mental events" is their nature as expressions of subjectivity and they are to be explained with reference to the closed system of motivations, as much as physical events demand to be explained with reference to the closed system of physical nature. The Davidsonian asymmetry between mental and physical events is therefore unsubstantiated.
Eliminato: , when the pre-givenness (Vorgegebenheit) of the world manifests itself, and in general

Eliminato: whenever

Eliminato: al and

Eliminato: of events

Eliminato:

Eliminato: If $b$

Eliminato: , this is no univocal definition. Granted that psychological phenomena are

Eliminato: recognized

Eliminato:

Eliminato: . In the first case, we focus on the unity of consciousness as far as we recognize it in others" bodily expressions; in the second case, we focus

Eliminato: which are taken to be 
Davidson's propensity to regard mental events as a subset of physical events is not accidental, however, but is due to the original sin of assuming an ontology of spatiotemporal events. Consciousness does not primarily appear among events and we learn to recognize consciousness in alter egos (as mental events proper) only secondarily, after being able to recognize spatiotemporal events (objects) as such. In other words, the "mental" is not primarily a matter of events and assuming the privilege of an ontology of spatiotemporal events (naturalism) necessarily subordinates the "mental". As soon as the mental is treated as an aspect of events, motivation is subordinated to efficient causality, and efficient causality is interpreted as naturally conducive to laws. When physics expunges causal accounts from strict laws, this operation, in phenomenological terms, is tantamount to preserving the constituted dimensions of efficient causality $(\alpha, \beta$ and $\gamma)$ and dismissing the original dimension of efficaciousness $(\delta)$. But, as soon as the mental becomes an attribute of events, consciousness and motivation become phenomenal residua, unresolved appearances, in the last instance and regardless of any will to the contrary, epiphenomena.

\section{References}

Black, M., (1956). "Why Cannot an Effect Precede Its Cause". Analysis 16 (16) 49-58.

Brough J.B., (2008). "Consciousness is not a Bag: Immanence, Transcendence, and Constitution in The Idea of Phenomenology", Husserl Studies, 24, 177-191.

Bunge, M., (2009). Causality and Modern Science, New Brunswick: Transaction Publishers.

Cartwright, N., (1980) "Do the Laws of Physics state the Facts?" Pacific Philosophical Quarterly, 61, 75-84.

Cartwright, N., (2004). "Causation: One Word, Many Things", Philosophy of Science, 71, 805-819.

Davidson, D., (1963) “Actions, Reasons, and Causes”, in Davidson 1980 3 19.

Davidson, D., (1967) “Causal Relations”, in Davidson 1980 149-162.

Davidson, D., (1969) “The Individuation of Events", in Davidson 1980 163180.

Davidson, D., (1970) “"Mental Events”, in Davidson 1980 207-227.

Davidson, D., (1971) “Agency”, in Davidson 1980 43-61.

Davidson, D., (1974) "Psychology as Philosophy", in Davidson 1980 ${ }_{z} 229$ 239.

Davidson, D., (1980) Essays on Actions and Events, Oxford; Clarendon Press. Davidson, D., (1982) "Empirical Content", in Davidson 2001,159-175.

Davidson, D., (1983) "A Coherence Theory of Truth and Knowledge", in Davidson 2001, 137-153.

Davidson, D., (1985) "Reply to Quine on Events", in LePore \& McLaughlin 1985, 172-176.

Davidson, D., (1991) “Three Varieties of Knowledge”, in Davidson 2001 205-220.

\begin{tabular}{|l|}
\hline Eliminato: : \\
\hline Eliminato: 2008, \\
\hline Eliminato: : \\
\hline Eliminato: , \\
\hline Eliminato: , \\
\hline Eliminimato: : \\
\hline Eliminato: , \\
\hline Eliminato: : \\
\hline Eliminato: , \\
\hline Eliminato: : \\
\hline Eliminato: , \\
\hline Eliminato: : \\
\hline Eliminato: : \\
\hline Eliminato: , \\
\hline Eliminato: : \\
\hline Eliminato: , \\
\hline Eliminato: , \\
\hline Eliminato: , \\
\hline
\end{tabular}


Davidson, D., (1993) “Thinking Causes”, in Davidson 2005, 185-200.

Davidson, D., (1995) "Laws and Cause”, in Davidson 2005 201-219.

Davidson, D., (2001) Subjective, Intersubjective, Objective ${ }_{\star}$ Oxford; Clarendon Press.

Davidson, D., (2005) Truth, Language and History ${ }_{\ddagger}$ Oxford Clarendon Press. Dowe, P., (2000), Physical Causation $\rightarrow$ Cambridge; Cambridge University Press.

Evnine S., (1991). Donald Davidson. Oxford: Polity Press.

Giere, R., (1999). Science Without Laws, Chicago: University of Chicago Press.

Honderich, T., (1988). A Theory of Determinism. Oxford: Clarendon Press,

Husserl, E., (1950) Ideen zu einer reinen Phänomenologie und phänomenologischen Philosophie. Erstes Buch: Allgemeine Einführung in die

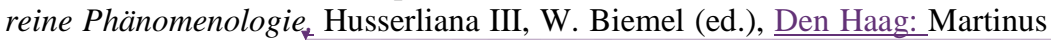
Nijhoff,

Husserl, E., (1952) Ideen $z u$ einer reinen Phänomenologie und phänomenologischen Philosophie. Zweites Buch. Phänomenologische Untersuchungen zur Konstitution ${ }_{\ddagger}$ Husserliana IV, M. Biemel (ed.), Den Haag: Martinus Nijhoff,

Husserl, E., (1954) Die Krisis der Europäischen Wissenschaften und die transzendentale Phänomenologie _Husserliana VI, W. Biemel (ed.), Den Haag: Martinus Nijhoff

Husserl, E., (1973) „ Die Idee der Phänomenologie. Fünf Vorlesungen Husserliana II, W. Biemel (ed.), Den Haag: Martinus Nijhoff,

Husserl, E., (1973), Cartesianische Meditationen und Pariser Vorträge Husserliana I, S. Strasser (ed.), Den Haag: Martinus Nijhoff,

Husserl, E. (2006) Späte Texte über Zeitkonstitution (1929-1934). Die CManuskripte $e_{z}$ Husserliana Materialien VIII, D. Lohmar (ed.), Dordrecht: Springer,

LePore, E. \& McLaughlin, B., (eds.) (1985) Actions and Events: Perspectives on the Philosophy of Donald Davidson New York: Blackwell.

Kim, J., (2000). Mind in a Physical World. Cambridge - Massachusetts: The MIT Press.

Salmon, W.C., (1998). Causality and Explanation Oxford: Oxford University Press.

Smith D. W., (1995). "Mind and Body" in The Cambridge Companion to Husserl,

edited by Barry Smith \& David Woodruff Smith, Cambridge: Cambridge University Press.

Van Fraassen, B., (1989). Laws and Symmetry, Oxford: Clarendon Press.

Von Wright, G.H., (1971). Explanation and Understanding , London: Routledge,

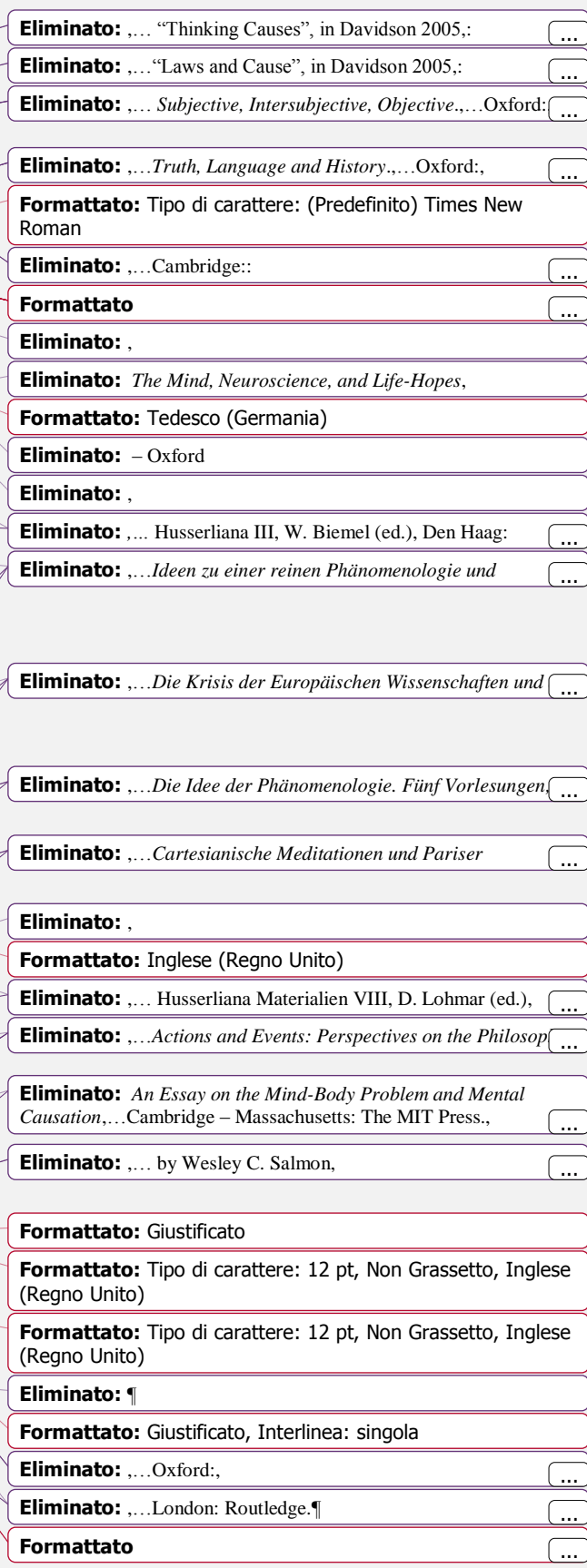

